\title{
Risk Factors for Stroke During Surgery for Carotid Body Tumors
}

\author{
K. E. A. van der Bogt • J. M. van Baalen · \\ J. F. Hamming
}

Published online: 17 August 2011

(c) The Author(s) 2011. This article is published with open access at Springerlink.com

The article by Gwon et al. [1] describes 17 carotid body tumor (CBT) resections, resulting in four patients $(23.5 \%)$ having a postoperative stroke and one case of permanent cranial nerve damage. The article once again shows that CBT surgery can be challenging because of neurovascular structures that are adjacent to or involved in the tumor. This is particularly true for larger CBTs that encompass the carotid arteries, as evidenced by the fact that three of four strokes were encountered after resection of a Shamblin III [2] tumor. When considering the very high percentage of postoperative stroke in the reported series, it should be stressed that CBTs are benign and slow-growing tumors in which conservative management should always be considered.

Furthermore, the authors state that preoperative embolization of CBT feeder vessels was performed to minimize intraoperative blood loss. Unfortunately, blood loss was not reported and it is therefore unclear whether embolization had indeed contributed to a decrease thereof in comparison to recent literature. Next, the authors conclude that embolization did not reduce the risk of stroke. Whether this statement is justified, considering the careful preoperative planning and subsequent selection bias, is questionable. However, the current data and the series we previously published [3] suggest that a decrease in blood loss might reduce perioperative morbidity. This can be achieved effectively by creating a craniocaudal dissection route whereby the tumor feeder vessels are ligated before the tumor and internal carotid artery are manipulated. In our experience, and from previous imaging studies from our institution [4], the main tumor feeder seems to be the

K. E. A. van der Bogt · J. M. van Baalen · J. F. Hamming ( $\square)$ Department of Surgery, Leiden University Medical Center, K6-41, P.O. Box 9600, 2300 RC Leiden, The Netherlands e-mail: j.f.hamming@lumc.nl ascending pharyngeal artery that branches from the external carotid artery at the dorsal side of the tumor and usually feeds the tumor from its cranial side. This area, which can also be referred to as dissection zone III as defined by Hallett et al. [5], is also the proximal site where most of the prominent neurological structures can be found. The craniocaudal approach therefore carries the advantage of early ligation of the prominent tumor feeder, less blood loss, and identification of the adjacent cranial nerves before manipulation of the CBT itself begins and substantial blood loss challenges the dissection. The effect might be comparable to early ECA division as described by the authors, which in their series had significant influence on the risk of stroke in larger tumors. Using the craniocaudal technique, we have not experienced stroke after any of 70 CBT resections over the past 20 years. Of note, all CBT patients in our institution receive heparin during dissection, allowing carotid artery clamping at any necessary stage.

Taken together, the article by Gwon et al. once again stresses the need for careful, multidisciplinary evaluation before considering high-risk surgical treatment. It also shows the importance of limiting blood loss during CBT surgery. In conclusion, we strongly advocate performing craniocaudal CBT dissection in specialized, high-volume centers.

Open Access This article is distributed under the terms of the Creative Commons Attribution Noncommercial License which permits any noncommercial use, distribution, and reproduction in any medium, provided the original author(s) and source are credited.

\section{References}

1. Gwon JG, Kwon TW, Kim H, Cho YP (2011) Risk factors for stroke during surgery for carotid body tumors. World J Surg 35(9):2154-2158. doi:10.1007/s00268-011-1167-7 
2. Shamblin WR, ReMine WH, Sheps SG, Harrison EG Jr (1971)

Carotid body tumor (chemodectoma). Clinicopathologic analysis of ninety cases. Am J Surg 122:732-739

3. van der Bogt KE, Vrancken Peeters MP, van Baalen JM, Hamming JF (2008) Resection of carotid body tumors: results of an evolving surgical technique. Ann Surg 247:877-884

4. van den Berg R, Wasser MN, van Gils AP, van der Mey AG, Hermans J, van Buchem MA (2000) Vascularization of head and neck paragangliomas: comparison of three MR angiographic techniques with digital subtraction angiography. Am J Neuroradiol 21:162-170

5. Hallett JW Jr, Nora JD, Hollier LH, Cherry KJ Jr, Pairolero PC (1988) Trends in neurovascular complications of surgical management for carotid body and cervical paragangliomas: a fifty-year experience with 153 tumors. J Vasc Surg 7:284-291 